\title{
Effect of gel time of 3D sand printing binder system on quality of sand mold/core
}

\author{
Yan Wang ${ }^{1,2}$, Rui-long Yu, ${ }^{1,2}$, Shao-kui Yin ${ }^{1,2}$, Rui Tan ${ }^{1,2}$, *Yan-chun Lou ${ }^{1,2}$ \\ 1. Shenyang Research Institute of Foundry Co., Ltd., Shenyang 110022, China \\ 2. State Key Laboratory of Light Alloy Casting Technology for High-end Equipment, Shenyang 110022, China
}

\begin{abstract}
Two important factors affecting the performance of sand mold/core generated by 3D printing (3DP) are strength and dimensional accuracy, which are not only closely related to the reactivity of furan resin and the phase transition of silica sand, but also the curing agent system of furan resin. This paper studies the influence of gel time on the strength and dimensional accuracy of a 3DP sand mold/core, taking the furan resin system as an example and using a sand specimen generated by a 3DP inkjet molding machine. The experiment demonstrates that the gel time of 3 to 6 min for the sand mixture suits 3DP core-making most under the experimental condition. However, it should be noted that under the same resin condition, the strength of a no-bake sand mold/core is higher than that of a 3DP sand mold/core. The dimensional accuracy of the sand mold/core does not change significantly when the gel time is less than $15 \mathrm{~min}$. Improving the activity of binder and developing ultra-strong acid with low corrosion shall be an effective way to improve the quality of the mold/core by $3 \mathrm{D}$ printing.
\end{abstract}

Key words: 3D sand printing; gel time; sand strength; dimensional accuracy

CLC numbers: TG221 ${ }^{+} .1 \quad$ Document code: A Article ID: 1672-6421(2021)06-581-06

\section{Introduction}

In the deep ocean of equipment manufacturing sector, the demand for complicated, precise, efficient and environment-friendly high-end castings has been increasing day by day ${ }^{[1]}$, which breeds a great opportunity for the popularization of 3D printing (3DP) technology. In recent years, 3DP technology has been applied in aerospace, national defense, automobile, medical and other fields. It can be predicted that 3DP core-making technology will become an important supplementary force to the processing of coated sand, cold box sand, and no-bake resin sand in the coming years and may even become one of the mainstream coremaking technologies.

Among the works published by researchers regarding $3 \mathrm{D}$ sand printing, Wang et al. ${ }^{[2]}$ took advantage of the 3DP process to achieve huge improvement of mold/ core design through topology optimization to reduce part weight by $50 \%$. Hackney et al. ${ }^{[3]}$ succeeded in manufacturing a sand mold by $3 \mathrm{D}$ sand printing to

*Yan-chun Lou

Male, Ph. D., Researcher. His research interest mainly focuses on the precision forming of high-performance lightweight alloy and stainless steel casting, especially the electrode slag remelting casting.

E-mail: louych@chinasrif.com

Received: 2021-05-28; Accepted: 2021-09-11 create parts for an automobile application. Kang et al. ${ }^{[4]}$ designed a 3DP skeletal sand mold containing an adaptive shell, functional cavities and a support, and ultimately cast aluminum test castings with improved mechanical properties. It was discovered that the permeability of the 3DP specimen decreased while temperature increased ${ }^{[5]}$. Printing parameters, which directly determined the resin content of the printing mold, immensely affected the tensile strength, loss on ignition, and printed sand density ${ }^{[6]}$.

However, current research stressed too much on the printing head and printing process, few research works were targeted at the binder system, which is one of important parts of 3DP. The binder system is the key factor to determine the performance of 3DP products, and it has been one of the bottlenecks holding up the development and application of 3DP technology.

The 3DP process has utterly different performance requirements on the binder as compared to the traditional no-bake resin sand process. For example, the binder system is required to have a higher curing speed, lower resin viscosity and higher purity for the 3DP process and so far the binders used in the 3DP process mainly include furan resin, phenolic resin, and inorganic binder.

During the $3 \mathrm{D}$ sand printing process, the substrate drops $0.2-0.6 \mathrm{~mm}$ after re-coating sand and jetting binder for one layer. If the curing rate of resin (binder) 
is too low with lower strength, a small amount of relative displacement will occur between the sand layers ${ }^{[1]}$. The goals of this study lie in determining the most suitable gel time of the bonding system for the 3DP process, whether and how much the displacement affects strength and surface quality of the sand $\mathrm{mold} / \mathrm{core}$

\section{Experiment procedures}

\subsection{Specimen preparation}

The sand specimens were prepared with the same silica sand, furan resin binder and sulfonic acid catalyst by no-bake resin sand method and 3DP method, respectively. In the preparation of no-bake sand samples, $1 \mathrm{~kg}$ sand was put into the sand mixer with $0.12 \%-0.3 \%$ catalyst (by sand weight) and mixed for $2 \mathrm{~min}$, then mixed with $1 \%$ furan resin for $30 \mathrm{~s}$. After that, the mixed sand was put into the 8 -character shape mold to complete the sample preparation within $1 \mathrm{~min}$, and then the tensile strength was measured at $24 \mathrm{~h}$.

When preparing the 3DP samples, the $0.12 \%-0.3 \%$ catalyst was mixed with silica sand by the continuous sand mill. Ten kilogram sand was mixed each time, and then the mixed sand was dried over $12 \mathrm{~h}$ in the sack at $25 \pm 2{ }^{\circ} \mathrm{C}, 45 \pm 5 \mathrm{RH}$. Then, the 3DP samples were printed on a Voxeljet VX200 printer using the prepared silica sand as powders and $1 \%$ (by sand weight) furan resin as spray binder. The printed samples were cleaned $2 \mathrm{~h}$ later after the printing finished, and the tensile strength at $24 \mathrm{~h}$ was measured. Figure 1 shows the 3D scanning diagram of the test sample.

\subsection{Determination of gel time}

As the 3DP mold/core was printed layer by layer, the hardening uniformity of mold/core had little effect on the strength of 3DP mold/core, the concept of surface hardness of green sand was introduced to define the gel time of 3DP sand mold/cores. After resin jetting on the sand, the $\mathrm{H}^{+}$of sulfonic acid in the catalyst began to catalyze the resin and carried on a cross-linking reaction. In a few minutes, the resin gelatinized and formed a reticular structure and partial cubic structure so that the sand mold/core was cured. The sand samples slowly

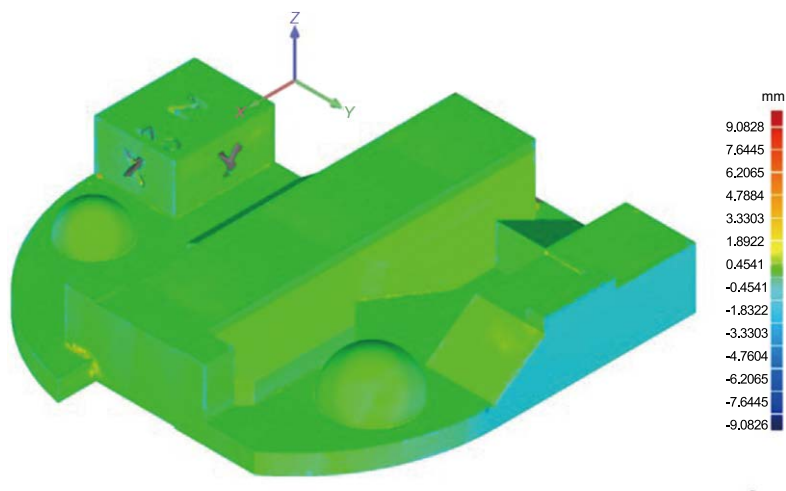

Fig. 1: Image of sand specimen scanned by laser scanner

turned from light green to dark green during this process.

For determining the gel time of resin no-bake sand, the timing started when the resin was added in the mixing sand process, and the surface hardness of the sand sample was continuously measured by the sand surface hardness tester in different positions. When the hardness of the specimen reached 45 , the time was defined as the gel time (also defined as the usable time). When the hardness achieved 95, it was defined as the stripping time. Meanwhile, for the 3DP samples, the timing began when the thickness of the printed sand mold was $3 \mathrm{~mm}$; defining of the gel time and stripping time was the same as above.

\section{Results}

\subsection{Effect of gel time on tensile strength}

Some researchers ${ }^{[7]}$ indicated that the gel time (or curing time) of 3DP had no effect on mechanical strength. However, this study has testified that the gel time of mixed sand had great effects on not only tensile strength, but also surface quality and dimensional accuracy. To change the gel time, a different amount of catalyst was added, and the tensile strength of samples by no-bake sand process and 3DP process were compared. As it was shown in Table 1 , the $24 \mathrm{~h}$ strength firstly increased with the extending of gel time and then became stable when the gel time was longer than $5 \mathrm{~min}$.

Table 1: Effect of catalyst addition amount on strength of no-bake resin sand

\begin{tabular}{cccc}
$\begin{array}{c}\text { Addition amount } \\
(\%)\end{array}$ & $\begin{array}{c}\text { Gel time } \\
(\mathrm{min})\end{array}$ & $\begin{array}{c}\text { Stripping time } \\
(\mathrm{min})\end{array}$ & $\begin{array}{c}24 \mathrm{~h} \text { tensile strength } \\
(\mathrm{MPa})\end{array}$ \\
\hline 0.12 & 30 & 100 & 1.50 \\
0.15 & 20 & 55 & 1.60 \\
0.18 & 13 & 51 & 1.60 \\
0.20 & 9 & 36 & 1.85 \\
0.22 & 5 & 28 & 1.65 \\
0.25 & 2 & 18 & 0.20 \\
0.30 & 1 & 12 & 0.05 \\
\hline
\end{tabular}


Table 2 listed the tensile strength of 3DP mold/core samples with different amounts of catalyst. The $24 \mathrm{~h}$ tensile strength firstly increased then decreased when increasing the gel time, and the highest strength was obtained at $6 \mathrm{~min}$. The surface of 3DP sand samples became rough and was deformed if the gel time got too long (more than $22 \mathrm{~min}$ ) or too short (1 min).
Because the minimum sand thickness measured by the molding sand surface strength tester was $3 \mathrm{~mm}$, the printing layer thickness was set at $0.3 \mathrm{~mm}$, printing speed was $20 \mathrm{~s}$ per layer, hence it took at least $3 \mathrm{~min}$ to print the mold. Therefore, when the gel time was less than $3 \mathrm{~min}$, there might be some errors during measurement.

Table 2: Effect of catalyst amount on strength and surface quality of 3DP mold/core

$\begin{array}{cccc}\text { Addition amount }(\%) & \text { Gel time }(\mathrm{min}) & \mathbf{2 4} \mathrm{h} \text { tensile strength }(\mathrm{MPa}) & \begin{array}{c}\text { Surface quality } \\ 0.12\end{array} 3^{25} \\ 0.15 & 0.35 & \begin{array}{c}\text { Rough surface and deformed } \\ \text { Rough surface and slightly deformed }\end{array} \\ 0.18 & 15 & 0.45 & \text { Rough surface and difficulty in cleaning } \\ 0.20 & 10 & 0.40 & \text { Rough surface and difficulty in cleaning } \\ 0.22 & 6 & 0.85 & \text { Clean surface } \\ 0.25 & 3 & 1.35 & \text { Clean surface } \\ 0.30 & 1 & 1.30 & \text { Rough surface }\end{array}$

Figure 2 showed a comparison between the $24 \mathrm{~h}$ tensile strength of 3DP sample and no-bake sand sample as a function of the gel time. When the gel time was less than $5 \mathrm{~min}$, the strength of no-bake sand was less than that of 3DP sand, and when the gel time was above $5 \mathrm{~min}$, the result turned out to be the opposite. The sand core fabricated by 3DP possessed the highest tensile strength when the gel time was between 3 to 6 min, which decreased significantly when the gel time was longer than $6 \mathrm{~min}$. As for the no-bake sand, only when the gel time was longer than $5 \mathrm{~min}$ did it possess satisfactory tensile strength.

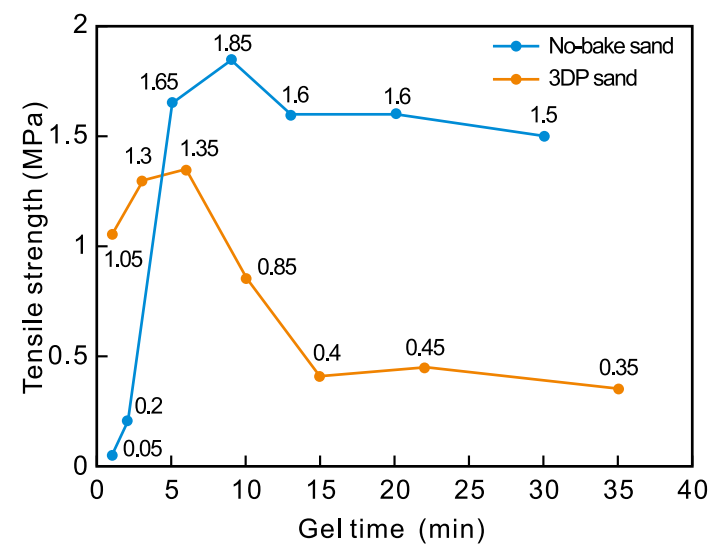

Fig. 2: $24 \mathrm{~h}$ tensile strength of samples with different gel times

\subsection{Effect of gel time on accuracy}

Table 2 indicated that when the gel time was longer than $10 \mathrm{~min}$, the strength of the 3DP specimen decreased and the sample surface was deformed (Fig. 3). The dimensional accuracy of the samples with the gel time of 1, 3, 6, 10, 15 min was analyzed. Figure 4 illustrated the 3DP samples with the gel time from 1 to $15 \mathrm{~min}$. The specimens with the gel time of 1 and 3 min were

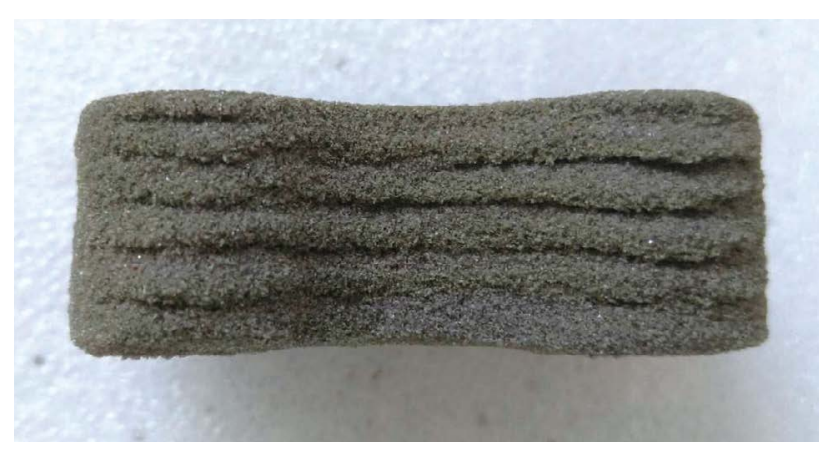

Fig. 3: Image of deformed sand specimen

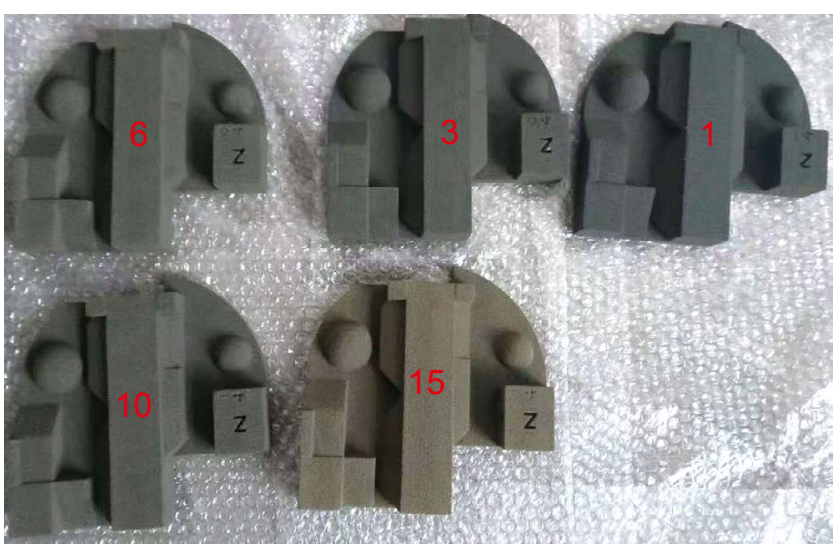

Fig. 4: Image of 3DP sand specimens with different gel times

dark green, during this time it was difficult to remove the sand on surface. While, the specimen with the gel time of 15 min was light green, which was fragile with a lower strength.

Table 3 illustrates the dimensional accuracy of each specimen. It can be found that gel time had little impact on the dimensional accuracy of the sand mold/core within $15 \mathrm{~min}$. 
Table 3: Dimensional accuracy of specimens with different gel times

$\begin{array}{ccccc}\begin{array}{c}\text { Gel time } \\ (\mathrm{min})\end{array} & \begin{array}{c}\text { Positive error } \\ (\mathrm{mm})\end{array} & \begin{array}{c}\text { Negative error } \\ (\mathrm{mm})\end{array} & \begin{array}{c}\text { Average error } \\ (\mathrm{mm})\end{array} & \begin{array}{c}\text { RMS error } \\ (\mathrm{mm})\end{array} \\ 1 & 0.1074 & -0.3722 & 0.2222 & 0.4099 \\ 3 & 0.1139 & -0.3379 & 0.2193 & 0.3888 \\ 6 & 0.1350 & -0.3326 & 0.2194 & 0.3817 \\ 10 & 0.1047 & -0.3877 & 0.2125 & 0.3886 \\ 15 & 0.2087 & -0.3319 & 0.2576 & 0.3877\end{array}$

\section{Discussion}

The above experiment proved that the higher tensile strength and the better surface quality of 3DP samples can be obtained when the gel time is between 3 to $10 \mathrm{~min}$. As the gel time increases from 3 to $10 \mathrm{~min}$, the $24 \mathrm{~h}$ tensile strength decreases from 1.35 to $0.85 \mathrm{MPa}$, decreased by about $37 \%$. What's more, the highest tensile strength of no-bake sand specimen is $1.85 \mathrm{MPa}$, which is $37 \%$ higher than that of the $3 \mathrm{DP}$ specimen.

\subsection{Sand compaction}

The density of 3DP specimen $\left(1.35-1.45 \mathrm{~g} \cdot \mathrm{cm}^{-3}\right)$ was less than that of no-bake sand $\left(1.45-1.55 \mathrm{~g} \cdot \mathrm{cm}^{-3}\right)$ because the sand spreading pressure in 3DP process was less than that of no-

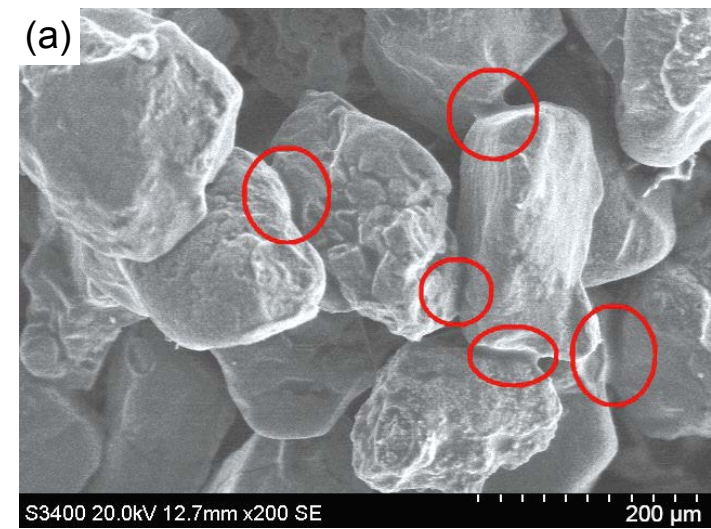

bake sand. The porosity of the 3DP specimen reached up to $40 \%$ because the raw sand concentration was up to $95 \%$ by the two-sieve screening method or the three-sieve screening method $^{[8]}$. The sand was covered with binder by capillary action without fully stirring as in the no-bake sand ${ }^{[9]}$. As illustrated in Fig. 5, the 3DP specimen showed fewer and smaller adhesion bridges compared with the no-bake sand specimen, which was the reason why the 3DP specimen had lower strength than nobake sand with the same amount of binder and catalyst. During the 3DP process, the liquid binder flowed by gravity and surface tension in the large space between sand grains because of lower compaction, resulting in a longer gel time, which would deteriorate the strength of the specimen.

Fig. 5: SEM images of no-baked (a) and 3DP sand (b) specimens

\subsection{Catalyst crystallization}

For better re-coating sand, the sand mixture was dried for more than $12 \mathrm{~h}$, and most of the solvent was evaporated, so the sulfonic acid crystallizes on the sand surface, as shown in Fig. 6. In the 3DP process, after the binder was printed on the sand, the sulfonic acid of catalyst needed to be dissolved in the binder, so as to provide the $\mathrm{H}^{+}$required for the curing of the resin. Therefore, a longer time was taken for 3DP sand to cure than no-bake sand with the same amount of catalyst or total acid amount, as shown in Tables 1 and 2. During the process of forming the network from the resin to the body structure, a considerable amount of acid was left undissolved, which cannot move to the adhesion bridge in the form of ions from

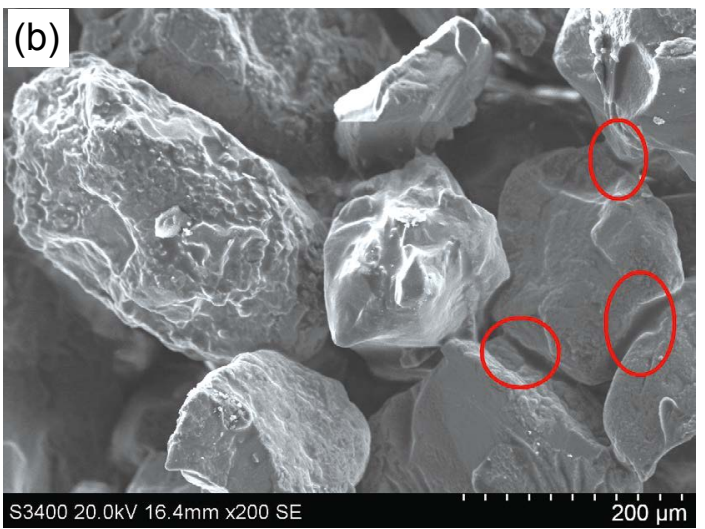

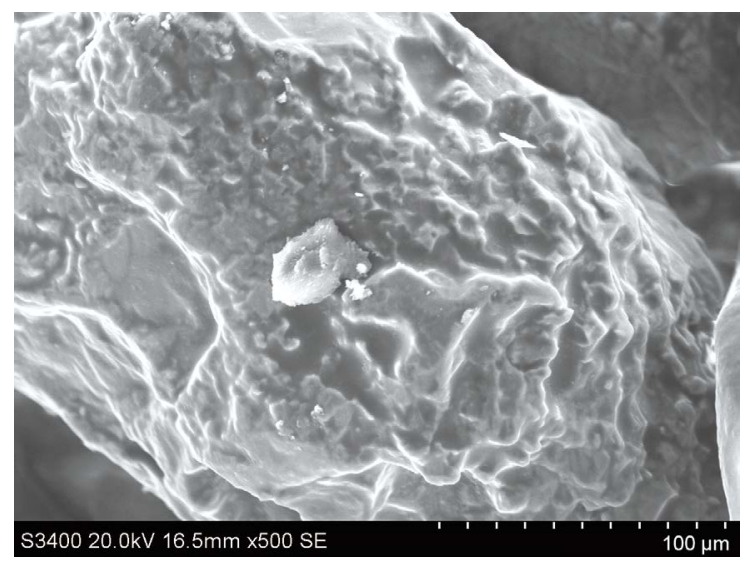

Fig. 6: SEM image of acid crystallization on sand 
liquid, resulting in an insufficient acid amount. Therefore, the catalyst in the 3DP did not fully function and the strength of the 3DP specimen was lower compared to the self-hardening one. In this case, when the gel time was longer, the acid of the catalyst reacting with binder was dissolved while the binder was being cured, so that the strength was lower. This was an unavoidable problem during the use of the sulfonic acid-based catalyst in the $3 \mathrm{DP}$ process. To reduce the gel time, excessive catalyst was added to increase the sulphur amount which would be corrosive to the re-coater. To sum up, the key point to solve this problem was to promote activity of a catalyst which could gel in a short time with less amount, or to develop a new catalyst without crystallization or corrosion. Besides, wet-recoating is another effective way to solve the above problems.

\subsection{Displacement between sand layer}

Volume shrinkage of liquid into solid and the movement by recoating are the two dominating means of displacement between sand layers. The displacement was $0.008 \%-0.2 \%$ in $X$ and $Y$ axis direction and $0.8 \%$ in $Z$-axis direction ${ }^{[10]}$. When the gel time was less than $1 \mathrm{~min}$ (which was too short), the binder printed in the sand layer was cured into semisolid so the binder permeation between layers was restricted; in this way, the strength declined. On the contrary, the surface became rough for over volume binder penetrated to the loose sand close to the mold/core. If the gel time was over $10 \mathrm{~min}$ (which was extra long), the binder was much less effective, the sand that could not cure in time would be moved by re-coater, resulting in displacement especially in $Z$-axis. Therefore, the strength was lower and the mold/core had a rough surface. In the appropriate gel time (3-6 min in this study), the strength reached its highest level. To verify the above speculation, the 8-character shape specimen was printed by VX200 printer in $X, Y, Z$ direction separately, and the bending and tensile strength were tested which was repeated 6 times in 3 weeks. Table 4 illustrates the test results.

Table 4: Strength comparison in different direction

\begin{tabular}{lcccccc} 
& \multicolumn{3}{c}{ Tensile strength (MPa) } & \multicolumn{3}{c}{ Bending strength (MPa) } \\
Direction & Average & Max & Min & Average & Max & Min \\
\cline { 3 - 5 } X direction & 1.674 & 1.713 & 1.627 & 3.180 & 3.579 & 2.965 \\
Y direction & 1.702 & 1.924 & 1.605 & 3.205 & 3.655 & 3.004 \\
Z direction & 1.019 & 1.262 & 0.963 & 2.226 & 2.671 & 1.925
\end{tabular}

It could be concluded from Table 4 that the strength in $Z$ axis was smaller than that in $X$ and $Y$ axis, which indicated that the displacement between sand layer ( $Z$ direction) had a profound effect on strength. Especially with longer gel time, the sand was removed by the re-coater in the re-coating direction so that the sand core deformed seriously (Fig. 2). Even when the gel time was between 6 to $10 \mathrm{~min}$, there would be slight deformation, which affected the surface quality of the sand mold/core, causing difficulty to clean.

\subsection{Penetration of binder}

The sand re-coated in the sand box could be regarded as a porous medium structure, as schematically shown in Fig. $7^{[12]}$.

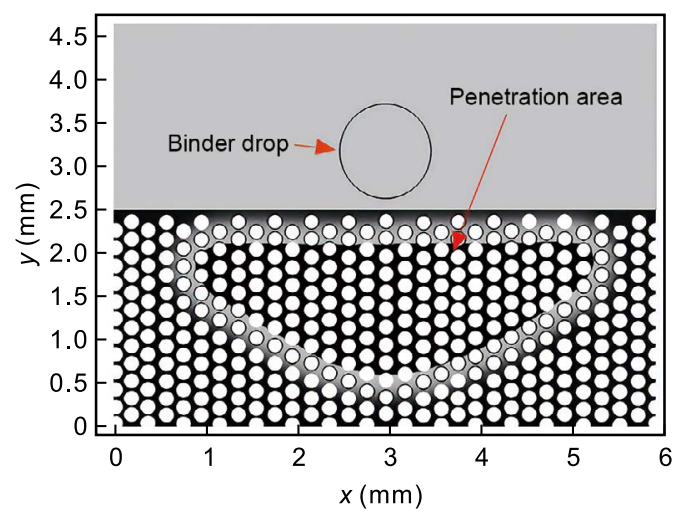

Fig. 7: Penetration schematic diagram with porosity of $40 \%^{[12]}$
In theory, when a binder with the viscosity of $10 \mathrm{MPa} \cdot \mathrm{s}$ was sprayed through a $0.6 \mu \mathrm{m}$ diameter nozzle, after contact with the raw sand surface, a spread area of about $2 \mathrm{~mm}$ in diameter would be formed within $0.4 \mathrm{~s}$, as shown in Fig. $8^{[12]}$. For comparison, a binder drop was printed on a quartzite plate. It could be seen the binder drop completely spread out within $0.4 \mathrm{~s}$.

According to the capillary permeability theory, the binder filled the gap between sand particles, and covered their surface ${ }^{[11]}$. When the binder contacted the catalyst, it started to react to form a mesh and/or the body structure, and both its surface tension and contact angle with the silica sand increased. Meanwhile, the viscosity sharply increased while the capillary radius reamained stable.

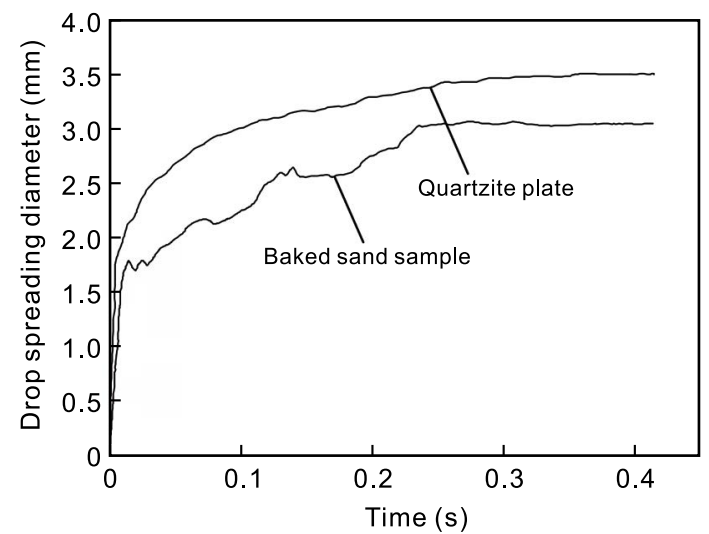

Fig. 8: Curve of drop spreading diameter on quartzite plate and baked sand sample ${ }^{[12]}$ 
Thus, the penetration would be blocked by the existing binder in the lower sand layer. That is to say, the gel time was much longer than $0.4 \mathrm{~s}$ which the drop penetrated freely after printing on sand bed, so that the binder would not be more evenly re-coated on the sand or form more adhesion bridges to improve performance even over a longer gel time. On the contrary, if the gel time is too long, the surface of mold/core would become rougher due to that the binder penetrates through the outline.

\section{Conclusions}

(1) The gel time has significant impact on the strength and quality of the surface. The most suitable gel time of the binder in the mixture was 3 to $6 \mathrm{~min}$ in this experiment. Only when the gel time was less than 6 min could the displacement between sand particles be reduced, thus improving the strength and surface quality of sand mold/core. The dimensional accuracy of the sand mold/core did not change significantly when the gel time was less than $15 \mathrm{~min}$.

(2) In the 3DP process, the compaction rate of the sand mold/ core is low, resulting in low number and small area of bond bridges, which causes the strength of the 3DP sample to be lower than that of no-bake sand. The prolonging of the gel time did not increase the number, area or strength of the binder-bonded bridge. On the contrary, it reduced the surface quality caused by the displacement between the sand layers.

(3) Sulfonic acid catalyst would crystallize and redissolve during 3DP process; therefore, sufficient acid is required to ensure proper gel time. Improving the activity of binder and developing ultra-strong acid with low corrosion shall be an effective way to improve the quality of the mold/core by $3 \mathrm{D}$ printing.

\section{Acknowledgements}

This research was financially supported by the Liaoning Science and Technology Plan Program (2019-ZD-0998) and the National Natural Science Foundation of China (Grant No. U1808216)

\section{References}

[1] Upadhyay M, Sivarupan T, Mansori EI M. 3D printing for rapid sand casting - A review. Journal of Manufacturing Processes, 2017, 29: 211-220.

[2] Wang J Y, Sama S R, Manogharan G. Re-thinking design methodology for castings: 3D sand-printing and topology optimization. International Journal of Metalcasting, 2019, 13(1): 2-17.

[3] Hackney P M, Wooldridge R. 3D sand printing for automotive mass production applications. International Journal of Rapid Manufacturing, 2017, 6(2-3): 134-54.

[4] Kang J W, Shangguan H L, Peng F, et al. Cooling control for castings by adopting skeletal sand mold design. China Foundry, 2021, 18(1): 18-28.

[5] Mitra S, Rodríguez de C A, Mansori El M. The effect of ageing process on three-point bending strength and permeability of 3D printed sand molds. The International Journal of Advanced Manufacturing Technology, 2018, 97(1-4): 1241-1251.

[6] Bryant N, Frush T, Thiel J, et al. Influence of machine parameters on the physical characteristics of 3D-printed sand molds for metal casting. International Journal of Metalcasting, 2020, 15(2): 361-372.

[7] Hackney P M, Wooldridge R. Characterisation of direct 3D sand printing process for the production of sand cast mould tools. Rapid Prototyping Journal, 2017, 23(1): 7-15.

[8] Voxeliet. GS19RP. https://strobel-quarzsand.de/Produkte_en / Giessereisand_en.html

[9] Yang $W$ D, Jia P F, Ma $Y Y$, et al. Modeling and simulation of binder droplet infiltration in 3D printing technology. Nanotechnology and Precision Engineering, 2017, 15(4): 246253.

[10] Hu P S. Molding sand. Shanghai Science and Technology Press, Shanghai China, 1994.

[11] Li H. Optimization of patternless casting manufacturing based on additive manufacturing technology. Master dissertation, Taiyuan: Taiyuan University of Technology, 2016. (In Chinese)

[12] Yang W D, Xu X W, Jia P F. Simulation and research of adhesive penetration in the 3DP technology. Manufacturing Technology \& Machine Tool, 2016, 10: 102-106. (In Chinese) 